\title{
Factors Affecting High Yielding Teff Varieties Adoption Intensity by Small Holder Farmers in West Showa Zone, Ethiopia
}

\author{
Dawit Milkias \\ Ethiopian Institute of Agricultural Research, Ambo Agricultural Research Center, Ambo, Ethiopia
}

Email address:

mkdave04@gmail.com

To cite this article:

Dawit Milkias. Factors Affecting High Yielding Teff Varieties Adoption Intensity by Small Holder Farmers in West Showa Zone, Ethiopia. International Journal of Economy, Energy and Environment. Vol. 5, No. 1, 2020, pp. 6-13. doi: 10.11648/j.ijeee.20200501.12

Received: March 9, 2020; Accepted: March 20, 2020; Published: April 21, 2020

\begin{abstract}
The objective of the study is to describe the socio-economic characteristics of households growing high yielding teff varieties; and to investigate the factors influencing intensity of adoption of high yielding teff by small holder farmers in the study area. Both primary and secondary data were used for the study. The primary data was collected by using questionnaire from randomly selected of 144 teff producer household heads from the study areas. Three districts namely Ambo, Dendi and Toke kutaye of West showa zone and four PAs from each district were purposively selected on the ground that they are the leading producer of teff. Descriptive statistics and econometric model were employed for analyzing the data. Descriptive analysis result shows that variables such as experience on teff, farm size and distance to the market from continuous variable and sex of household head, participating on farmers association, extension, availability of credit, attending demonstration and agricultural extension training were significantly influences high yielding teff varieties adoption intensity. Tobit model result reviled that age of house hold head, market distance and farmers association were negatively influences adoption while, intensity of adoption of high yielding teff varieties was positively influenced by experience on teff farming, farm size, average income, extension, availability of credit, training, demonstration and owning radio for the technologies. The overall finding of the study underlined the high importance of institutional support by strengthening extension services, attention also should be given to the research and extension linkages, and frequent training must be organized for development agents and supervisors about existing and newly developed improved technologies and new methods of agricultural practices.
\end{abstract}

Keywords: Ambo, Intensity, Teff, Tobit, Household

\section{Introduction}

\subsection{Background of the Study}

Agricultural growth in Sub-Saharan Africa is considered to be low and not much driven by technological change [12]; [32]. There is ample evidence showing that the adoption of agricultural technologies as well as the provision of agricultural extension programs can be important stimuli for improvements in agricultural productivity [10].

Agriculture is the basis of Ethiopia economy. It contributes to over 50 percent of the GDP and 90 percent of raw materials requirement of the country's small and mediumsized industries. It is also estimated that agriculture provides employment for about $85 \%$ of labour force [20]. Agriculture in Ethiopia is the foundation of the country's economy. Ethiopia's demand for food grains continues to increase because of population pressure, while supply remain short.

The wide variability in agro-ecological conditions helps the country to produce different kinds of cereals, fruits and vegetables, and different species of livestock. However, Ethiopian agriculture is characterized by low productivity. Over the last two decades it was not able to produce sufficient food to feed the country's rapidly growing population. The level of technology is almost basic and productivity per hectare is perhaps among the lowest in the world. [26] indicates that in high agricultural potential areas of Ethiopia (i.e. with high and reliable rainfall), in which crop based system predominates and population densities are highest, productivity is constrained by lack of knowledge, 
lack of finance and unavailability of appropriate improved technologies.

Cereals are the major food crops both in terms of the area coverage and volume of production and accounts for $95 \%$ of agricultural production in Ethiopia and contributed $86.68 \%$ of the grain production. Maize, wheat, and teff are the most important cereals in terms of volume, accounting for a total of $77 \%$ of all cereal production [4] while maize, teff, wheat and sorghum have made $26.80 \%, 16.76 \%, 15.81 \%$ and $16.20 \%$ of the grain production respectively [6]. From the cereal crops, Eragrostis Teff (Zucc.) is the most preferred staple food by majority of the Ethiopian population and its center of origin is in Ethiopia. Teff has high energy, phosphorus, calcium and iron contents [13]. Moreover, the economic contribution of teff indicates that real Teff output on average accounted for $6.1 \%$ of the real GDP, while growth in real Teff output accounted for $6.4 \%$ of the total growth in real GDP i.e., $0.67 \%$ of the 10.7 percent growth in real GDP [14].

However, the current production system of Teff cannot satisfy the consumers' demand due to backward and lack of modern technologies. Its production and productivity is still very low due to traditional agronomic practices, nutrient deficiencies and susceptibility of the crop to lodging [28]. Various types of cereal crops are being produced in different parts of Ethiopia that serve as a staple food for the majority of people. Teff is one of the most important cereal crops in Ethiopia in general and West Showa in particular. It serves as a source of both food and cash income. In order to achieve food security, a lot of attempts have been made by the government in Ethiopia over the last three decades but failed to increase the expected agricultural production and bring about noticeable change in the life of the smallholder farmers. In this regard, [5] suggested that one of the reasons for the existing structural food insecurity in the country is the low level of technology development, which acts as the principle barriers to the efficient utilization of the country's natural resource. Even though different extension approaches have been implemented in the study area, it did not bring major or expected impacts on the productivity of smallholder farmers. Despite large efforts that have been made to scale up new farming technologies like Teff improved varieties, the decision of smallholder farmers to adopt vary widely based on various technical and nontechnical factors that affect their decision.

\subsection{Objectives of the Study}

\subsubsection{General Objective}

The main objective of the study was to assess factors affecting high yielding teff varieties Adoption intensity by small holder Farmers in the west shewa zone.

\subsubsection{Specific Objectives}

To describe the socio-economic characteristics of households growing high yielding teff technologies; and to investigate the factors influencing high yielding teff technology adoption intensity by small holder farmers in the study area.

\section{Empirical Studies on Intensity of Agricultural Technology Adoption}

Intensity of adoption is defined as the level of use of a given technology. When technology is adopted it is important to understand the extent to which the technology has been used by the intended group. [27] stipulated intensity of adoption as a measure of depth of adoption in terms of parameters such as the number of hectares planted with improved seed or the amount of fertilizer applied per hectare.

The concept is necessary as adopters may claim that they have adopted the technology but comparatively they have not met the required standards [7]. Similarly, as different researches points out intensity use normally provides a correct measure on policy reform. For instance, low intensity may indicate that the technology introduced is not effective although it has been adopted. This avoids the generalization of technology having been adopted but in actual fact only a small amount is actually being used.

Literature reveals that adoption of a particular technology is influenced by a number of factors. These factors have been classified into four broad categories namely demographical, institutional, and environmental and farmers' subjective perception of agricultural technology [1]. Examples of demographical factors include education level, gender, experience, age, religion, and marital status. Institutional factors include extension services, input and output marketing system, credit facilities, land tenure system, information, and communication infrastructure.

However, small-scale farmers in developing countries are farm households who are engaged in both production and consumption of the same products. Smallholder farmers in many rural areas are semi-subsistent producers and consumers partially integrated into imperfect rural markets. The theory of farm household economics has demonstrated that when institutional factors are imperfect, production and technology adoption decisions are influenced by the level of poverty and asset ownership of the farmer [12]. This implies that assuming imperfections in credit, input and output markets, household characteristics and assets including family labor force and livestock and non-livestock asset endowments would be important factors in technology adoption decisions.

Many adoption studies conducted show that the use of agricultural technologies is strongly linked to the asset base [21]. Based on the same economic theory, point out that resource endowment is one of the major determinants of the observed adoption behavior, where lack of access to capital and inadequate farm size could significantly impede adoption decisions. Thus, [21] observe that the use of agricultural technology by a farmer is a function of livelihood assets owned by farmers that are influenced by policies, institutions and processes. Based on the above reviews, this study modeled livelihood assets of farmers integrated with institutional processes to influence adoption of improved teff varieties. 


\section{Methodology of the Study}

\subsection{An Overview West Showa Zone}

The study was conducted in Oromia National Regional State, West Showa administrative zone, which is found between $817^{\circ}-956^{\circ}$ North and $371^{\circ}-3845^{\circ}$ West. It is found in central part of the region, though some areas do incline to Western part. The zone is bounded with Amhara regional state in the Northern part, East Wollega and Horro Guduru Wollega in the West and North West, Jimma Zone in the South West, South West Showa zone in the South East and North Showa zone in the North East.

West Showa Zone is $170 \mathrm{Km}$ long from north to south and $183 \mathrm{Km}$ wide from East to West. Ambo is the capital of zone and far $114 \mathrm{Km}$ to the West of Addis Ababa on the main way from Addis to Nekemt. On the basis of current border delineation, Zone has area of $15,185 \mathrm{Km}^{2}$ which covers $4.51 \%$ of Oromia national regional state. West Showa Zone has 529 PAs and 39 urban kebeles. This Zone has the population of $2,071,974$ from this $88.4 \%$ resides in rural areas and the remaining $11.6 \%$ are urban dwellers. The total household heads in the west Showa zone is 250,268 male and 39,823 female households' farmers. The land use pattern of the zone shows that 614,967 ha is cultivated land; 104,902 ha are covered with forest and 250,233.52 ha are grazing land. The major crops produced in the zone are, Teff, wheat, Maize, barley, Faba bean and etc ([34]).

\subsection{Sampling Procedure, Sample Size Determination and Analysis}

This study used cross sectional research design in which cross sectional data were collected and used for analysis.
Purposive sampling was used to select district and villages for the survey while random sampling technique was used to draw respondents for the interview. The Villages identification was made through reviewing secondary data on production potential of teff and dissemination of the technologies and area coverage of the crop.

Three districts (Ambo, Dendi and Toke kutaye) were selected for the survey. Selected villages include Bojigebisa, Amaro, Elamujelina and Bayokurbi from Ambo; Awash bole, Boloxo awash, Lokloka, and Wamora sako in Dendi; and Birbirsa dogoma, Toke meti, Ajobedo and Kolba lencha from Toke kutaye. In each village at least 12 farmers were drawn for interview and made a sample size of 48 respondents in each district and hence a total sample size of 144 respondents. A structured questionnaire was used for collecting information from sampled farmers.

Descriptive and econometric methods of data analysis were used to evaluate the relationship between independent and dependent variable. Descriptive statistics such as means, standard deviation, frequency distributions and cross tabulations were used to describe the data. Econometric analysis that employed for the study was Tobit model for intensity of adoption of high yielding teff varieties. The dependent variable used in the Tobit model was intensity of adoption of high yielding teff varieties which is treated as a continuous variable. It is the amount of improved high yielding teff that the farmer used which is measured in quintal. The explanatory variables in this study are those variables which are thought to have influence intensity of adoption of high yielding teff varieties in the study area. These include socio-economic, institutional, demographic and psychological factors which had influenced the adoption and intensity of the varieties by farm households.

Table 1. Definition of the variables and units of measurement.

\begin{tabular}{lll}
\hline Variables & Symbols & Descriptions of the Variables \\
\hline Age of HHHs & AGEHH & Age of household head (year). \\
Education level & EDULEVEL & Education of HHH (number of years in school) \\
Sex of Household & SEXHH & Sex of Household (=1, Male,=0, female) \\
Farm size & FARMSIZ & Farm size of household (hectare). \\
Experience on Teff & EXPRTEFF & Teff farming experience of HHHs in years \\
Livestock & TLPU & Livestock owned by the farm HH (TLU). \\
Access to credit & CREDIT & Access of farmer to fertilizer and seed on credit $(=1$, if yes; =0, otherwise) \\
Average income & INCHH & Average annual earnings of the farmers $/$ ETB/ \\
Extension Contact & CONTEXA & Frequency of extension contacts \\
Demonstration & PARTDMS & Farmers host demonstration on their farm, dummy variable (=1, if yes; =0, otherwise). \\
Training & PARTRAI & Farmer attended formal agricultural training, dummy variable (1=, if yes; =0, otherwise). \\
Man equivalent & MAEQV & Labor availability (man equivalent). \\
Market distance & MARKDIST & Distance of the respondents' house from input and output market $(\mathrm{km})$. \\
Owning Radio & RADIO & Owning radio at home (=1, if yes;=0, otherwise). \\
Farmers association & FARASSO & Participation on farmers association status of Households \\
\hline
\end{tabular}

\section{Result and Discussion}

\subsection{Socio-Economic Characteristics of Respondents}

Summary statistics of the sample farm households are discussed under this section. The dataset contains 144 farm households and of these, about $54.2 \%$ households were adopters i.e. they planted at least more than one of the improved teff varieties during the 2018 cropping season. According to descriptive analysis, some variations were observed between adopters and non-adopter in terms of household characteristics, farm and institutional factors (tables 2 and 3). In this study, a total of 15 independent variables were identified and out of these variables 9 of them revealed significant association with the high yielding teff 
varieties adoption intensity.

Descriptive statistics result revealed that from the total sample respondents, $87.5 \%$ were male and the rest $12.5 \%$ were female (Table 3). From the adopter sample respondents, $92.31 \%$ and $7.69 \%$ were male and female-headed households respectively. The majority of female household adopters were found in low adoption category which indicates that they are less capable in adopting high yielding teff varieties as compared to their male household counterparts in the study area. Therefore, sex is statistically significant and positive relationship with the adoption decision at $10 \%$ level of significant. The result of this study is in agreement with results of previous researchers who have reported the significant relationship between sex and adoption of agricultural technologies [17, 22].

In this study, the average farm size of sample respondents was found to be 1.0069 hectare with standard deviation of 0.229 hectare. The maximum land size owned by the sample households was 1.75 hectare while the minimum is 0.5 hectare. The average land holding for adopter group was 1.2 hectare while that of non-adopter group is 0.7 hectare. The difference in land holding between adopters and non-adopters is statistically significant at $1 \%$ significance level. The result indicates that, farm households with relatively large farm size had adopted the variety more than those with small farm size. A more experienced farmer appears to be more knowledgeable and may have a lower level of uncertainty about new technologies. The mean difference of farming experience between adopters and non-adopters was found to be significant at $1 \%$ significance level. This indicates that farming experience influences adoption of high yielding teff varieties in the study area.

Sample households were located at a mean distance of 2.09 kilometers away from the nearest main market. Adopters were far a mean of 1.9 kilometers away from their main market while non-adopters were 2.3 kilometers far. A mean difference of market distance between adopters and nonadopters was statistically significantly different at 1 percent significance level. This implies that farmers who are close to markets are more likely to adopt high yielding teff varieties than those who reside far from the main market.

In this study, $89(61.81 \%)$ of sample households were found to have access to formal credit. Adopters and nonadopter farmers were found to access formal credit with varying proportion being $83.33 \%$ and $36.36 \%$ from their groups respectively. Therefore, the analysis result revealed that, access to credit service shows statistically significant association with the adoption decision at $1 \%$ level of significance (Table 3). This implies that, farmers having an access to use credit service had a capacity to purchase agricultural inputs. Probably, it is also enhanced to adopt high yielding teff varieties than otherwise.

Table 3 indicates that from the total sample respondents $45.83 \%$ of total sampled households have participated in demonstration and the rest $54.17 \%$ did not participated. The result indicated that participation on demonstration significantly and positively influences the adoption of high yielding teff varieties in the study area. From the total sample respondents 144 farmers interviewed $23.61 \%$ of them had attended training at different level of frequency while $76.39 \%$ did not attend training program related to high yielding teff varieties. The result indicated that participation on training positively influences the adoption of high yielding teff varieties at $1 \%$ significance level in the study area.

Participation of farmers in social organization had positive influence on adoption of high yielding teff varieties at $1 \%$ level of significance. With this regard 98.72 percent sample respondents were member of farmer's association. Organizing of farmers to be a member of farmers association would facilitate access to credit, access to extension information and access to market. This implies strengthening and expansion of rural association is of paramount importance to enhance adoption of high yielding teff varieties production.

The major sources of agricultural information for farmers are extension agents. Regular contact with extension agents make farmers being aware of new technologies and how they can be applied. Contact with extension agent or availability of extension services is perhaps the single variable that emerged significantly in most of the research work on technology transfer and adoption ([24]; and [30]). It is hypothesized contact with extension workers will increase a farmer's probability of adopting technologies. From adopters group $85.9 \%$ the respondent contact frequently and from the non-adopter groups, and $14.1 \%$ of respondent contact not frequently with extension agents. Final, the analysis result indicated that, extension contact shows statistically significant association with the adoption decision at $1 \%$ level of significance.

From continuous variables (Table 2), age of household head, education level, livestock holding, average income of farmers and availability labour had not statistically significant relation with the adoption decision. While owning radio from dummy variables (Table 3 ) had not statistically significant relation with high yielding teff varieties adoption intensity in the study area. Summary of the overall descriptive results of this study is presented in tables 2 and 3 below.

Table 2. Summary of means of continuous variable.

\begin{tabular}{|c|c|c|c|c|c|c|c|c|}
\hline \multirow{2}{*}{\multicolumn{2}{|c|}{ Variables }} & \multicolumn{2}{|c|}{ Adopters } & \multicolumn{2}{|c|}{ Non Adopters } & \multicolumn{2}{|c|}{ Total Sample } & \multirow{2}{*}{ t-value } \\
\hline & & Mean & SD & Mean & SD & Mean & SD & \\
\hline 1 & AGEHH & 50.3205 & 9.64095 & 49.2424 & 9.87625 & 49.8264 & 9.73016 & 0.5096 \\
\hline 2 & EDULEVEL & 2.07692 & 0.84928 & 1.89394 & 0.8436 & 1.99306 & 0.84866 & 0.1984 \\
\hline 3 & MAEQV & 5.0000 & 1.32165 & 4.84394 & 1.16594 & 4.92847 & 1.25083 & 0.4576 \\
\hline 4 & INCHH & 9006.4 & 2862.4 & 5675.1 & 3080.2 & 7479.6 & 3390.9 & -6.7200 \\
\hline 5 & EXPRTEFF & 6.32051 & 2.22438 & 1.78788 & 3.05093 & 4.24306 & 3.46863 & $-10.2847 * * *$ \\
\hline 6 & FARMSIZ & 1.20038 & 0.2378 & 1.10096 & 0.2123 & 1.14653 & 0.22901 & $2.6498 * * *$ \\
\hline
\end{tabular}




\begin{tabular}{lllllllll}
\hline \multirow{2}{*}{ Variables } & \multicolumn{3}{c}{ Adopters } & \multicolumn{3}{c}{ Non Adopters } & \multicolumn{2}{l}{ Total Sample } \\
\cline { 2 - 9 } & Mean & SD & Mean & SD & Mean & SD & t-value \\
\hline 7 & TPLU & 6.62463 & 2.98925 & 6.0508 & 2.9431 & 6.36163 & 2.9717 & 0.2497 \\
8 & MARKDIST & 1.91026 & 1.11874 & 2.30303 & 1.20217 & 2.09028 & 1.17022 & $2.0286^{* * *}$ \\
\hline
\end{tabular}

Source: own survey data, 2018. $* * *$, denote significant at $1 \%$, levels of significance respectively.

Table 3. Summary of descriptive statistics for Dummy variables.

\begin{tabular}{|c|c|c|c|c|c|c|c|}
\hline \multirow{2}{*}{\multicolumn{2}{|c|}{ Variables response }} & \multirow{4}{*}{$\begin{array}{l}\text { Category } \\
\text { Female } \\
\text { Male }\end{array}$} & \multirow{3}{*}{$\begin{array}{l}\text { Adopters } \\
\text { Frequency } \\
6\end{array}$} & \multicolumn{3}{|c|}{ Non adopters } & \multirow{4}{*}{$\frac{\text { p-value }}{0.058 *}$} \\
\hline & & & & $\%$ & Frequency & $\%$ & \\
\hline \multirow{2}{*}{1} & \multirow{2}{*}{ SEXHH } & & & 7.69 & 12 & 18.18 & \\
\hline & & & 72 & 92.31 & 54 & 81.82 & \\
\hline \multirow{2}{*}{2} & \multirow{2}{*}{ FARASSO } & No & 1 & 1.28 & 9 & 13.64 & \multirow{2}{*}{$0.004 * * *$} \\
\hline & & Yes & 77 & 98.72 & 57 & 86.36 & \\
\hline \multirow{2}{*}{3} & \multirow{2}{*}{ CONTEXA } & No & 11 & 14.1 & 24 & 36.36 & \multirow{2}{*}{$0.000 * * *$} \\
\hline & & Yes & 67 & 85.9 & 42 & 63.64 & \\
\hline \multirow{2}{*}{4} & \multirow{2}{*}{ CREDIT } & No & 13 & 16.67 & 42 & 63.64 & \multirow{2}{*}{$0.000 * * *$} \\
\hline & & Yes & 65 & 83.33 & 24 & 36.36 & \\
\hline \multirow{2}{*}{5} & \multirow{2}{*}{ PARTDMS } & No & 35 & 44.87 & 43 & 65.15 & \multirow[t]{2}{*}{$0.015^{* *}$} \\
\hline & & Yes & 43 & 55.13 & 23 & 34.85 & \\
\hline \multirow{2}{*}{6} & \multirow{2}{*}{ PARTRAI } & No & 47 & 60.26 & 63 & 95.43 & \multirow[t]{2}{*}{$0.000 * * *$} \\
\hline & & Yes & 31 & 39.74 & 3 & 4.55 & \\
\hline \multirow{2}{*}{7} & \multirow{2}{*}{ RADIO } & No & 35 & 44.87 & 30 & 45.45 & \multirow[t]{2}{*}{0.944} \\
\hline & & Yes & 43 & 55.13 & 36 & 54.55 & \\
\hline
\end{tabular}

Source: own survey data, 2018. ***, *** denote significant at $1 \%, 5 \%$ and $10 \%$ levels of significance respectively.

\subsection{Factors Affecting of High Yielding Teff Varieties Adoption Intensity: From the Tobit Estimation}

In this section, selected explanatory variables were used to estimate the Tobit model to analyze the factors affecting high yielding teff varieties adoption behavior of sample respondents on the technology in the study area. The estimates of parameters of the variables expected to influence adoption of high yielding teff varieties are displayed on table 4 .

Finally, a set of 15 explanatory variables ( 8 continuous and 7 dummy variables) were included in the model for analysis. These variables were selected on the basis of theoretical explanations, personal observations and the results of the survey studies. The impression of these variables on the dependent variable is discussed below.

Table 4. Maximum likelihood estimates of variable determining adoption of high yielding teff varieties among respondent farmers.

\begin{tabular}{|c|c|c|c|c|c|}
\hline Variables & Estimated Coef. & Std. Err. & t-ratio & P-value & Marginal effect \\
\hline AGEHH & -0.0582 & 0.0267 & $-2.18 * *$ & 0.031 & -0.0582 \\
\hline EDULEVEL & -0.1953 & 0.3014 & -0.65 & 0.518 & -0.1953 \\
\hline SEXHH & 0.3472 & 0.7884 & 0.44 & 0.660 & 0.3472 \\
\hline EXPRTEFF & 0.5393 & 0.0942 & $5.72 * * *$ & 0.000 & 0.5392 \\
\hline FARMSIZ & 2.8708 & 1.0594 & $2.71 * * *$ & 0.008 & 2.8708 \\
\hline INCHH & 0.00024 & 0.000085 & $2.80 * * *$ & 0.006 & 0.00024 \\
\hline MAEQV & 0.0004 & 0.1704 & $0.000 * * *$ & 0.998 & 0.00039 \\
\hline TLPU & -0.1273 & 0.0876 & -1.45 & 0.148 & -0.1273 \\
\hline MARKDIST & -0.4847 & 0.2361 & $-2.05 * *$ & 0.042 & -0.4845 \\
\hline FARASSO & -1.2859 & 0.4419 & $-2.91 * * *$ & 0.004 & -1.2859 \\
\hline CONTEXA & 4.3614 & 1.7012 & $2.56 * *$ & 0.011 & 4.3614 \\
\hline CREDIT & 3.2315 & 0.7209 & $4.48 * * *$ & 0.000 & 3.2315 \\
\hline PARTRAI & 2.2085 & 0.5483 & $4.03 * * *$ & 0.000 & 2.2085 \\
\hline PARTDMS & 1.2114 & 0.4879 & $2.48 * *$ & 0.014 & 1.2114 \\
\hline RADIO & 1.0588 & 0.4966 & $2.13 * *$ & 0.035 & 1.0588 \\
\hline \multicolumn{6}{|c|}{ Number of obs $=144$, LR chi $2(15)=216.53$ Prob $>$ chi $2=0.0000$} \\
\hline \multicolumn{6}{|c|}{ Log likelihood $=-232.91183$ Pseudo $\mathrm{R} 2=0.3173$} \\
\hline
\end{tabular}

Source: own survey data, 2018. ***,** denote significant at $1 \%$ and $5 \%$ levels of significance respectively.

Age of HH: The result indicates that age of household head significantly influenced the probability of adopting high yielding teff varieties at $5 \%$ significance level. The marginal change result implies that a year increase in the age of the sample respondents reduces the probability of adopting high yielding teff varieties by $5.8 \%$. As expected the probability of adopting is negatively influenced by age, which means that the older farmers are less likely to adopt high yielding seeds. This result is consistent with [2].

Experience on Teff (EXPRTEFF): It was positive and statistically significant at $1 \%$ level of significance. This implies that the more the years of experience in farming, the 
higher the likelihood of adoption of high yielding teff varieties. The marginal effect result show that as farm experience on teff farming increases by one year, intensity of adopting high yielding teff varieties increases by 5.3 percent. This result confirms the study done by [33], who indicated that a more experienced grower might have a lower level of uncertainty about innovation performance.

Farm size (FARMSIZ): It was found that farm size had positively and significantly influenced the probability of adoption of high yielding teff varieties at less than $1 \%$ significant level. The marginal effect result implies that with each additional hectare of land increasing the probability of adoption of high yielding teff varieties by 2.9 percent. The implication is that farmers with large farm size are more likely to adopt the high yielding teff varieties than those farmers who have small land size. The result of this study confirms the earlier findings of $([9,19])$.

Market Distance (MARKDIST): The finding of distance of the respondents' house from input and output market is negatively and significantly associated the probability of adopting high yielding teff varieties at less than 5\% significance level. The negative association suggests that the likelihood of adopting high yielding teff varieties declines as the distance from market center increases. The marginal effect result indicates that, as the distance of the respondents' house from input and output market is far by kilometer, the probability of adopting high yielding teff varieties decreases by 4.8 percent. This result is consistent with [25].

Farmers association (FARASSO): The estimated parameter for participating on farmers association is significant at $1 \%$ level and is negatively related to adoption of high yielding teff varieties. This result indicates that farmers who are members of various local organizations are less likely to adopt high yielding teff varieties. The result of marginal effect implies that being member of local organizations, citrus paribus, reduces adopting high yielding teff varieties by 1.3 percent. This result is consistent with [23].

Access to credit (CREDIT): The model result indicates that the variable access to credit had positively and significantly influenced the likelihood of adoption of high yielding teff varieties at less than $1 \%$ significance level. The marginal effect result show that having access to credit by a percent increases the probability of adopting high yielding teff varieties by 3.2 percent. This result confirms the study done by [9], due to the fact that access to credit service commands the farmers' financial resources to buy inputs for improved high yielding teff varieties production.

Average farmers income (INCHH): The model result was found positive and highly significant at $1 \%$ significance level. Marginal change result indicate that as the farmers average income increases, the probability and intensity of adopting high yielding teff varieties increase by 0.024 percent. This implies that any increase in the income of the farmers would lead to increased intensity of adoption of high yielding teff varieties. In this case, farmers with higher income are more likely to have the necessary funds to finance the initial cost of adopting improved varieties, for example, improved seeds, fertilizers, and the labor requirement for planting and subsequent farm operations. The result is similar to [31].

Man equivalent (MAEQV): Availability of family labor is significantly influencing the adoption of high yielding teff varieties at $1 \%$ significance level. The result of the model shows that if the household head has increase in the number of productive family labor in man equivalent in one unit, the intensity of adoption of high yielding teff varieties increases by 0.003 percent. This may be due to the fact that, the availability of family labor increases the capability of the household to manage the commodity properly. It may not need to hire additional labor for production purpose. This creates an opportunity to save the money and accumulate capital to purchase production inputs. The finding of this study confirms the findings of $[29,15,18]$.

Extension contact (CONTEXA): Frequency of extension service contact was a positive and statistically significant variable in determining intensity of use of high yield teff varieties at $1 \%$ level. Households that had regular contacts with extension agents are more enlightened through advisory services and therefore appreciate the more, benefits of a new technology. The marginal effect result shows that an increase in frequency of contact with extension agent increased the intensity of use of improved varieties by 4.3 percent. This finding agrees with [16].

Owning Radio (RADIO): is positively affected the probability of adoption of high yielding teff varieties at less than 5\% significance level. The model result implies that, farmers who owned radio at their home are more probably tend to adopt high yielding teff varieties by 1.01 percent than those households who have no radio at their home. It is important resources for adopting agricultural technologies in such a way that farmers could easily afford technologies and also farmers are mostly exposed to new and updated information available on what they can be done [23].

Attending demonstration (PARTDMS): It was found that attending demonstration had positively and significantly influenced the probability of adoption of high yielding teff varieties at 5\% significant level. The result of marginal effect implies that, in number of participating on agricultural demonstration increases, the probability of adopting high yielding teff varieties increases by 1.2 percent. Farmers who have opportunity to attend on demonstration of agricultural technologies are more likely to use high yielding teff varieties than those farmers who have no similar opportunity. This result goes along with the study done by $[9,8]$.

Participating in training (PARTRAI): The model result indicates that attending on agricultural extension training had positively and significantly influenced the probability of adoption of high yielding teff varieties at $1 \%$ significant level. An increase in attendance in extension training increases probability of adoption and intensity of use of high yielding teff varieties by $2.2 \%$ percent. This implies the need to give emphasis to strengthening institutional supports to improve farmers' access to extension services and their participation in extension to enhance adoption of high 
yielding teff varieties.

\section{Conclusions and Recommendations}

\subsection{Conclusion}

The study was conceived with the objective of identifying key factors influencing probability of adoption and intensity of adoption of high yielding teff varieties in west showa zone of Oromia region Ethiopia. The Tobit model was adopted to analyze the intensity of adoption of high yielding teff varieties adoption decision because of the simultaneous nature of adoption of the two decisions. This study showed that age of household head, experience on teff farming, farm size, average income, labour, participation on social organization, extension contact, availability of credit, agricultural extension training, attending demonstration and owning radio for obtaining information were significantly influenced the process of high yielding teff varieties adoption intensity.

\subsection{Recommendations}

Currently, there is no short cut for substantial and dramatic increases in production of cereal crops in general teff varieties in particular without improved seeds. Therefore, to sustain the positive contribution of the extension service to the adoption of improved and high yielding teff varieties, strengthening extension services is necessary. In addition, attention also should be given to the research and extension linkages, and frequent training must be organized for development agents and supervisors about existing and newly developed improved technologies and new methods of agricultural practices.

\section{References}

[1] Adesina, et al. 1993. Technology characteristics, farmers' perceptions and adoption decisions: ATobit model application in Sierra Leone. Agricultural Economics 9: 297-311.

[2] Alene, A. Poonyth, D. and Hassan, R. (2000). Determinants of adoption and intensity of use of improved maize varieties in the Central Highlands of Ethiopia: A Tobit Analysis. Agrekon 39 (4): 633-643.

[3] Alemu D., et al., 2008). The maize seed system in Ethiopia: challenges and opportunities in drought prone areas. African Journal of Agricultural Research, 3 (4).

[4] ATA (Agricultural Transformation Agency). 2016. Transforming agriculture in Ethiopia. Annual report $2015 / 2016$

[5] Bellay Kassa, 2002. Agricultural Extension in Ethiopia: The case of participatory demonstration and training extension system. V. 18, No. 1, 2002.

[6] CSA (Central Statistical Agency). 2016. - Agricultural Statistics Abstract: Agriculture". Addis Ababa, Ethiopia.

[7] CIMMYT. 1993. The adoption of agricultural technology: A guide for survey Design. Mexico, D. F. CIMMYT.
[8] Chilot Yirga, 1994. Factors influencing adoption of new wheat technologies in the Wolemera and Addis Alem Areas of Ethiopia. An M. Sc. Thesis Presented to the School of Graduate Studies of Alemaya.

[9] Dawit et al, 2018: Determinants of Agricultural Technology Adoption: The Case of Improved Highland Maize Varieties in Toke Kutaye District, Oromia Regional State, Ethiopia.

[10] Duflo, E. Kremer, M. and Robinson, J. (2006). Understanding Technology Adoption: Fertilizer in Western Kenya: Preliminary Result from Field Experiments. MIT, NBER, CEPR and BREAD; Harvard University, NBER and BREAD; and Princeton University.

[11] Degnet Abebaw and Belay Kassa, 2001. Factors influencing adoption of high yielding maize varieties in South West Ethiopia: An Application of Logit Analysise, Quarterly Journal of International Agriculture. 40 (2): 149151 .

[12] De Janvry, Alain \& Elisabeth Sadoulet. (2010). Agriculture for Development in Sub-Saharan Africa: Business-as-Usual or New Departures? Journal of African Economies, 19, (2): pp 7 39. https://doi.org/10.1093/jae/ejp028

[13] Fufa Bekabil, et al, 2011. "Strengthening the teff value chain in Ethiopia." Mimeo, Agricultural Transformation Agency (ATA), Addis Ababa, Ethiopia.

[14] Fantu, 2015: Summary of ESSP Working Paper 89, Productivity and efficiency of small holder Teff farmers in Ethiopia.

[15] Hassen Beshir, 2014. Factors affecting the adoption and intensity of use of improved forages in North East Highlands of Ethiopia, American Journal of Experimental Agriculture.

[16] Knowler D, Bradshaw B (2007). Farmers' adoption of conservation agriculture: A Review and Synthesis of Recent Res. Food Policy 32: 25-48.

[17] Kyei, L., Foli, G. \& Ankoh, J. (2011). Analysis of factors affecting the technical efficiency of cocoa farmers in the Offinso District, Ashanti Region, Ghana. Retrieved April 8, 2012 from http://www.scihub.org/AJSMS.

[18] Mavunganidze, Z., et al, 2013. Factors affecting the choice of conservation agriculture practices adopted by smallholder cotton farmers in Zimbabwe. African Journal of Agricultural Research. 8 (17): 5-8.

[19] M. Kassie, B. Shiferaw and G. Muricho, 2011: Agricultural technology, crop income, and poverty alleviation in Uganda. World Development, 2011, $39 \quad$ (10): 1784 10.1016/j.worlddev.2011.04.023.

[20] MEDaC (Ministry of Economic Development and Planning), 1999. Survey of the Ethiopian Economy. Review of post reform development, (1992/931997/98. MEDAc, Addis Ababa.

[21] Michelle Adato and Ruth Meinzen-Dick 2002: Assessing The Impact Of Agricultural Research On Poverty Using The Sustainable Livelihoods Framework.

[22] Mulugeta, E. Belay and Dadi, L. (2001). "Determinants of Adoption of Physical Soil Conservation Measures in Central Highlands of Ethiopia. The Case of Three Districts of North Shewa". Journal of Agricultural Economics. 
[23] Regasa Dibaba et al, 2019: Determinants of high yielding wheat Varieties Adoption by smallholder farmers: Evidence from Ethiopia.

[24] Paudel, P. and Matsuoka, A. 2008. Factors influencing of improved maize varieties in Nepal: A case study of Chitwan district. Australian Journal of Basic and Applied Sciences. 2 (4): 823-834.

[25] Raju Ghimire et al, 2015: Adoption Pattern and Welfare Impact of Agricultural Technology: Empirical Evidence from Rice Farmers in Nepal.

[26] SG (Sasakawa Global) 2000/Ethiopia project, 2002. Activities and outputs: An assessment 1993-2001 Sasakawa Global 2000, Addis Ababa, Ethiopia, August 2002.

[27] Shiferaw et al, 2008: Technology adoption under seed access constraints and the economic impacts of improved pigeon pea varieties in Tanzaniae", Agricultural Economics, 39 (3): 309323.

[28] Teklay T., et al, (2016): Agronomic and economic evaluations of compound fertilizer applications under different planting methods and seed rates of Teff [Eragrostis Teff (Zucc.)
Trotter] in Northern Ethiopia. Journal of the Dry lands, 6 (1): 409-422.

[29] Tsibuk Berhe 2015: Factors Affecting Adoption of Quncho Teff Variety: The Case of Medebayzana Woreda, NorthWestern Administrative Zone Of Tigray Region, Ethiopia.

[30] Tura et al, 2010. Adoption and continued use of improved maize seed in Ethiopia. African Journal of agriculture research. 17: 2350-2358.

[31] Udensi E. Udensi et al 2011: Adoption of selected improved cassava varieties among smallholder farmers in South-Eastern Nigeria.

[32] World Bank (2008). World Development Report 2008, Agriculture for Development. The World Bank. Washington, DC.

[33] Yishak et al, 2011: Determinants of Adoption of Improved Maize Technology in Damot Gale, Wolaita, Ethiopia.

[34] Zone office ARD, 2018: Activity performance reports. West showa zone, oromia region Ethiopia. 